\title{
Economic Perspectives on the Impact of COVID Vaccines
}

\section{OPEN ACCESS}

Manuscript ID:

ECO-2021-09023730

Volume: 9

Issue: 2

Month: March

Year: 2021

P-ISSN: 2319-961X

E-ISSN: 2582-0192

Received: 10.01.2021

Accepted: 15.02.2021

Published: 01.03.2021

Citation:

Sangamithra, A., and S.

Thilagavathy. "Economic

Perspectives on the Impact

of COVID Vaccines."

Shanlax International

Journal of Economcis, vol. 9, no. 2, 2021, pp. 52-54.

DOI:

https://doi.org/10.34293/ economics.v9i2.3730

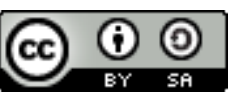

This work is licensed under a Creative Commons Attribution-ShareAlike 4.0 International License

\section{A. Sangamithra}

Professor, Department of Economics, Bharathiar University, Coimbatore, Tamil Nadu, India

(D) https://orcid.org/0000-0003-4761-8150

\section{S. Thilagavathy}

Ph.D. Research Scholar, Department of Economics

Bharathiar University, Coimbatore, Tamil Nadu, India

\begin{abstract}
Vaccination and the impact on health on the world's people is very difficult to exaggerate. The main aim is to treat people with mental health issues and substance use of disorder. Vaccination is crucial in terms of ensuring the overall health conditions and well-being. The development of vaccines is an expensive and lengthy process. Depreciation is high and takes multiple candidates and long years to produce a licensed vaccine. The access to vaccines that prevent life-threatening infectious diseases remains not equal to all the population. The benefits of vaccination derive from health and economic benefits and the health benefits have diminishing returns as a result of high-risk individuals been vaccinated first. Economic benefits depend both on the health benefits and on how reduced risk of infection and death translates into a leading general economic activity. Department of Government is required to perform a systematic economic analyses of vaccines and to justify their given pressure on both private and public finances on a global level; provoke in the year 2008 financial crash. Mostly, the government supports charities and non-governmental organizations, where people invest in these, with the hope of improving the health conditions.
\end{abstract}

Keywords: Vaccine, Diseases, Activity, Infection, Justify, Programs, Expectancy, Morbidity

\section{Introduction}

The development of vaccines is an expensive and lengthy process. Depreciation is high and takes multiple candidates and long years to produce a licensed vaccine. The access to vaccines that prevent life-threatening infectious diseases remains not equal to all the population. It estimates that vaccines have prevented six million deaths annually from vaccine - preventable disease. For the past few decades, the vaccine industry and scientific community have asked to respond immediately to epidemics of H1N1 influenza, Zika, Ebala and now it is SARS COV-2. By 2055, it is estimated that the earth's population to reach almost ten billion given by (Department of Economic and Vaccines that can prevent most of the disease and prolong life expectancy across many countries.

(Charlene M.C Rodrigues et al. 2020). Pandemic will cause high demand for vaccines all around the world. Both serologic studies and clinical studies will need to confirm which populations remain at the highest level of risk once the vaccines are available and could form the basis for establishing a fair vaccine for allocation system. Group of seven countries has already called it a global organization in which the planning must get starts while the vaccine development activity proceeds. COVID-19 - a pandemic situation has caused the hundreds or thousands of people upended the lives in billions and causes a trillion dollars in economic loss. Life is unlikely to return to normal life. What's unique about India is that it has the expertise for low-cost per-unit vaccine production of vaccines. 
Due to the low budget vaccine making history, new products against COVID-19 will be of great use in many low-income countries worldwide, benefiting millions of people who cannot afford expensive vaccines. India has manufactured the oral polio vaccine and distributed it freely across the country as part of the polio eradication initiative by the WHO. Prices send signals about consumer preferences and thus stimulate producers to make more of what people want. Pricing in a pandemic is complicated and fraught. The policy puzzle involves balancing lower prices to ensure access to essential medications, vaccines, and tests, and adequate revenue streams to provide manufacturers incentives to make the substantial, risky investments needed to develop products in the first place. Vaccines can be powerful tools for preventing potential outbreaks of epidemic infectious diseases from becoming humanitarian crises. Developing these vaccines requires investment. However, evidence shows what it would cost to successful development, an epidemic infectious disease caused by vaccine portfolio is scarce.

\section{Benefits of Vaccination}

The benefits of vaccination derive from health and economic benefits and the health benefits have diminishing returns as a result of highrisk individuals been vaccinated first. Economic benefits depend both on the health benefits and on how reduced risk of infection and death translates into higher general economic activity. The latter relationship is relatively unknown. If the elderly are vaccinated first, for example, will the young go back to work, or will they still be worried about infection? An epidemiological model of COVID-19 vaccination suggests diminishing but a linear impact of dose on disease until society approaches the level required for herd immunity. Our framework allows the diminishing-returns factor and the linear epidemiological factor to receive some weight. Putting an enormous weight on the diminishing returns factor would mean that health and economic activity improves so quickly as we vaccinate.

In contrast, broad weight on the linear function would mean that more people need to be vaccinated, approaching close to herd immunity, before most of the economic benefits are realized (IDB 2020). COVID-19, a pandemic situation outbreak is foremost a public health crisis; it is also caused damage to the global economy. The government is spending trillions of dollars to fight against the negative economic impact; still, until there is a vaccine or any other treatment is available, the financial cost will continue to be felt worldwide.

Table 1: Types of Vaccines for COVID-19

\begin{tabular}{|c|c|}
\hline Virus & Type of Vaccine \\
\hline Ebola & $\begin{array}{l}\text { Adenovirus Type } 5 \\
\text { Vector }\end{array}$ \\
\hline $\begin{array}{l}\text { Lassa, Nipah HIV Filovirus } \\
\text { HPV Cancer indications } \\
\text { Zika Hepatitis B }\end{array}$ & $\begin{array}{l}\text { DNA plasmid vaccine } \\
\text { Electroporation } \\
\text { devices }\end{array}$ \\
\hline SARS & $\begin{array}{l}\text { Plasmid DNA, } \\
\text { Needle- Free Delivery }\end{array}$ \\
\hline $\begin{array}{l}\text { HAV, ZIKV, FMD, SIV, } \\
\text { RSV, DENV }\end{array}$ & $\begin{array}{l}\text { Deoptimized live } \\
\text { attenuated vaccines }\end{array}$ \\
\hline $\begin{array}{l}\text { MERS, , TB, Chikungunya, } \\
\text { Zika, MenB, plague }\end{array}$ & ChADOx 1 \\
\hline LASV, EBOV, MARV, HIV & MVA encoded VLP \\
\hline HIV, RSV & $\begin{array}{l}\text { Ad26 (alone or with } \\
\text { MVA boost) }\end{array}$ \\
\hline Influenza & $\begin{array}{l}\text { Adenovirus-based } \\
\text { NasoVAX expressing } \\
\text { SARS2-CoV spike } \\
\text { protein }\end{array}$ \\
\hline MERS & $\begin{array}{l}\text { Ad5 S (GREVAXTM } \\
\text { platform) }\end{array}$ \\
\hline $\begin{array}{l}\text { Flu, Rotavirus, Norovirus, } \\
\text { West Nile virus, Cancer }\end{array}$ & Plant-derived VLP \\
\hline
\end{tabular}

\section{Economic Benefits of Vaccines}

- (Shearley, 1999) with the comparison of other public health interventions (Bloom et al. 2005). Vaccines are highly beneficial based on a population level and also cost-effective. Department of government is required to perform an economic analysis and vaccine programs to justify their purchase give the pressure on both private and public finance globally; this provoked in the year 2008 financial crash.

- The vaccination program has a fair direct cost, including infrastructure and vaccine purchase to run the program and maintain the cold chain, health care/ administrative personnel. Sometimes 
government supported the charities and non - governmental organizations who invest in developing the health conditions.

- The decrease rate in morbidity and mortality is associated with the successful vaccination programs, to a combination of both direct and indirect protection, lead to reduced incidences of disease and their associated treatment and health care costs. This leads to economic growth with the less amount of money which ows to the value through few medical tests, procedures, treatments and less time off work by COVID-19 patients / parents.

- (Deogaonkar et al. 2012), Additionally, we use the combination of vaccines, e.g., DTap / IPV / $\mathrm{H} 1 \mathrm{~b} / \mathrm{HepB}$, which protects the increased number of diseases with no additional infrastructure costs, i.e., the number of injections for one child within an existing immunization programs.

\section{Conclusion}

A global financial system that supports through the end-end process and large scale manufacturing sectors and formation, which ensures fair allocation and protects the private sector partners from significant financial losses, will cause a critical components of future COVID-19 pandemic alertness.

\section{References}

Bajinka, Ousman, et al. "Busting Myths about Sars-Cov-2 Viral Pandemic to Non-Medical Personnel." Annals of Clinical Trials and Vaccines Research, vol. 3, no. 2, 2020.

Berry, Donald A., et al. "A Cost/Benefit Analysis of Clinical Trial Designs for COVID-19 Vaccine Candidates." PloS One, vol. 15, 2020.
Chakraborty, Chiranjib, and Govindasamy Agoramoorthy. "India's cost-effective COVID-19 Vaccine Development Initiatives." Vaccine, vol. 38, 2020, pp. 7883-7884.

Cox, Jeff. "Vaccine News Gives a much-needed Boost to the Economic Outlook." $C N B C$, 2020.

Gouglas, Dimitrios, et al. "Estimating the Cost of Vaccine Development against Epidemic Infectious Diseases: A Cost Minimization Study." The Lancet, vol. 6, no. 12, 2018, pp. 1386-1396.

Hotez, Peter J., and Maria Elena Bottazzi. "Developing a Low-cost and Accessible COVID-19 Vaccine for Global Health." PLOS Neglected Tropical Diseases, vol. 14, 2020.

Kohli, Michele, et al. "The Potential Public Health and Economic Value of a Hypothetical COVID-19 Vaccine in the United States: Use of Cost-Effectiveness Modeling to Inform Vaccination Prioritization." Vaccine, vol. 39, 2021, pp. 1157-1164.

Lurie, Nicole, et al. "Developing Covid-19 Vaccines at Pandemic Speed." The New England Journal of Medicine, 2020, pp. 1969-1973.

Masterson, Victoria. "Equal Access to COVID-19 Vaccines could be Worth Billions." World Economic Forum, 2020.

Neumann, Peter J., et al. "Consideration of ValueBased Pricing for Treatments and Vaccines is Important, Even in the COVID-19 Pandemic." Health Affairs, vol. 40, 2021, pp. 53-61.

Rodrigues, Charlene M C, and Stanley A Plotkin. "Impact of Vaccines; Health, Economic and Social Perspectives." Frontiers in Microbiology, vol. 11, 2020.

\section{Author Details}

Dr. A. Sangamithra, Professor, Department of Economics, Bharathiar University, Coimbatore, Tamil Nadu, India, Email ID: a.sangamithra@gmail.com

S. Thilagavathy, Ph.D. Research Scholar, Department of Economics, Bharathiar University, Coimbatore, Tamil Nadu, India, Email ID: thilagavathyjothi545@gmail.com 